\title{
Analysis on the Construction of Entrepreneur Business Model under the "Internet Accelerated Speed" Environment
}

\author{
Xuejie Zhao \\ Business School, Hohai University, Nanjing, China \\ Email: 2516191892@qq.com
}

How to cite this paper: Zhao, X.J. (2019) Analysis on the Construction of Entrepreneur Business Model under the "Internet Accelerated Speed" Environment. Open Access Library Journal, 6: e5304. https://doi.org/10.4236/oalib.1105304

Received: March 1, 2019

Accepted: March 17, 2019

Published: March 20, 2019

Copyright $\odot 2019$ by author(s) and Open Access Library Inc.

This work is licensed under the Creative Commons Attribution International License (CC BY 4.0).

http://creativecommons.org/licenses/by/4.0/

\section{(c) (i) Open Access}

\begin{abstract}
Presently, Under the impact of the Internet, competition among enterprises is no longer just a competition between product prices, commodity logistics, talent reserves, supply chains, etc., but also involves the use of efficient Internet technologies to build competitive business model [1]. In this environment, entrepreneurship is facing enormous opportunities and challenges, entrepreneurs need to better deal with the Internet, this double-edged sword. Therefore, it is of great significance to explore the business model of entrepreneurship under the background of "Internet Accelerated Speed" ("Internet+") and to provide entrepreneurs with new ideas for entrepreneurship.
\end{abstract}

\section{Subject Areas}

Economics

\section{Keywords}

Internet+, Construct, Business, Model

\section{Introduction}

A new round of industrial revolution and technological revolution is gradually emerging. Under the background of the times, entrepreneurs face unprecedented challenges and opportunities. A reasonably effective business model is an important means of exploiting the potential value of entrepreneurial opportunities and a vital part of the entrepreneurial process. With the development and popularization of Internet technology, the Internet is playing an increasingly important role in the development of the industry, and the Internet has gradually become a new economic form. At the third session of the Twelfth National 
People's Congress in 2015, Premier Li Keqiang mentioned: "Developing 'Internet+' action plans to promote the integration of mobile Internet, cloud computing, big data, and the Internet of Things with modern manufacturing, and promote the healthy development of e-commerce, industrial Internet and Internet finance, guide Internet companies to expand the international market." During the two sessions, the "Internet+" was formally incorporated into the national strategic level. Under the "Internet+" environment, entrepreneurs have a lower threshold to start their own businesses, more entrepreneurial choices, and new changes have taken place in product content, marketing and talent demand.

Entrepreneurs will face more opportunities and challenges. Business model is the connection point between entrepreneurial opportunity and business plan, and it is the core of enterprise operation, which determines whether the enterprise can succeed or not, and whether it can survive and develop in the fierce market competition. However, due to the lack of a clear understanding of the mature and effective business model, the current entrepreneurial group is prone to fall into a blind state in the process of entrepreneurship, and the failure rate is relatively high.

\section{The Basic Form of Business Model in the "Internet+" Environment}

\subsection{The Connotation of "Internet+"}

"Internet+" is not a simple combination of traditional industries and the Internet. In fact, "Internet+" is a comprehensive, all-round, three-dimensional technical mean which is based on customer needs, driven by innovative technologies, focusing on interaction and experience, building a match with the information age, and the law of market development, thereby promoting the transformation and upgrading of traditional industries [2]. The use of the Internet involves a variety of information technologies, such as the Internet of things, big data, cloud computing, social computing, and so on. Through the comprehensive use of these technologies, to build a large database, through the analysis of the database, to obtain useful value information, complete pre-market research, locate user needs, find entrepreneurial opportunities, and then help entrepreneurs to implement targeted strategic adjustment, technological innovation, product development. "Internet + " is extremely malleable and can be combined with a wide range of industry industries. Whether in the traditional industry or emerging industries, it can be seen. "Internet + goods" appeared "Taobao", "Vipshop" and other e-commerce; "Internet + service" appeared "Didi Dache", "Mei Tuan" and other information service platforms; "Internet + communication" appeared Communication tools such as "QQ" and "WeChat". To realize the transformation and upgrading of the industry and realize the optimal allocation of social resources, we must make good use of "Internet+" to maximize its utility.

\subsection{Basic Concept of Business Model}

Peter Drucker, a management scientist, once pointed out that the competition 
between enterprises is not between different products, but between business models. This shows the importance of business models in the process of entrepreneurship.

Business model refers to the combination of six core issues in a specific market, which are related to each other in the aspects of enterprise strategy, structure, economy and so on. It can be divided into three levels: economy, operation and strategy [3]. And the business model's analysis unit is not a single product, a single enterprise, or even a single industry, but the entire cross-border collaboration system around the central enterprise.

\subsection{The Basic form of Business Model under the "Internet+" Environment}

Profit is the essence of business, and all business activities are carried out around the goal of "making money". The realization of its goal is closely related to the trading structure between relevant stakeholders. The key of transaction structure is information chain. So the most important change of the Internet to the business is to change the information link of the business link, cause the revolution of the information link, thus achieve the revolution of business patterns and business model. With the information chain as the entry point, the basic form of the business model in the Internet era is obtained [4].

The first form is the "mouth" pattern. By means of the Internet, each object is connected by a node, which is the entry point [4]. Nodes are like key figures in a community partner, connected to each person or object. This model is the "mouth" model, is the most basic one. To attract the attention of a group of consumers in a way that makes them interested in the product or activity they operate, in which the "way" adopted by the enterprise is the node.

The second form is the "Line" pattern. "Line" mode refers to the combination of one or more products and entrances, just like a line, connecting objects to objects, allowing them to interact and function [4]. This is the combination of traditional industry and the Internet, that is, the combination of traditional products and Internet entry, which is defined as the "line" model.

The third form is the "platform" pattern. If, not a product, selling a product through an entrance, but a variety, range of products, then, is the "platform" pattern, such as Taobao, JDcom. Using nodes to form a platform, and then gradually expand the platform, after a series of evolution, formed another basic model- "net" mode.

The fourth form is the "net" pattern. Connect people and things in a world that is not connected or less connected through the Internet to form a net. Whether via a central port or a connection without a central port, a net is formed, which is called net mode. The "net" mode can be analogous to the complicated and diversified "mouth" mode.

The fifth form is the "big data" pattern. Entrepreneurs or enterprises based on the information in this net, real-time, dynamic analysis, and apply it to business decisions, this is the "big data" model. Ant Financial Services Group, the Ali 
Department, has used big data to help fund companies develop new products, help insurance companies with differential pricing, help banks with customer churn warnings, help merchants better find customers and understand customers. Ant Financial Services Group's operating capital is 2.2 trillion, with 622 million users, but its bad debt rate is only $1 \%$. That's the charm of big data.

The sixth form is the "cloud-computing" "pattern." Cloud" is actually a metaphor of the Internet. Cloud computing is the use of the Internet to access storage or run on the remote server side of the application, data or services. The "cloud computing" mode refers to connecting all the nodes. "Cloud computing" refers to this model all the nodes together, the nodes may be a resource, the resource pool is formed, it may be a port, the port and tube, to form a "cloud pipe end. The calculation basis of the "cloud computing" model is grid computing, which is characterized by ultra-large scale, virtualization, high reliability, and high scalability.

The seventh form is the "circle" pattern. Through the above model of cross-border cooperation, the formation of an ecological circle, in the process of development can be integrated into the ecological circle dominated by others, but also can continue to expand itself. The relationship between the biosphere can be contained or intersected. Essentially, this circle forms an ecosystem about business. In this system, each subject can develop through the constant creation and transmission of value. For example, Ma Yun's business empire, logistics, products, finance, services and so on to form a huge business ecosystem.

Summing up, the "mouth" mode and "net" mode are both basic models. "Line" pattern, "platform" pattern, all around the user, in which the entry is the key. The basic mode of the fourth, fifth, sixth forms is the network mode, and the network mode is resource-based. In the Internet age, the marginal cost of information tends to be zero, the distance of information channel tends to zero, the linear information extends to the network of information, all things are information nodes [4]. In this context, entrepreneurs make good use of these points, which is the key to entrepreneurial success.

\section{The Basic Composition of Business Model in the "Inter- net+" Environment}

In the "Internet+" environment, according to the definition of business model and the understanding of business model, it is mainly composed of four parts: value proposition, profit model, resource ability and external effect [5]. There are many basic elements in each of these sections.

\subsection{Value Proposition}

The value proposition is a key part in the business model. It is a kind of choice for the enterprise to provide the problem value to which market and how to provide the value. And it is a preliminary position of the enterprise. The main components of value proposition are products and services, as well as target 
markets. Among them, product service is the basic value content provided by the enterprise, and the company engages in various business activities to complete this value provision. High quality products and services are of great significance to improve the competitiveness of enterprises. The target market refers to the specific object of the enterprise providing value service, that is, the customer group in the general sense. The correct choice of the target market is the key to the success of the enterprise.

\subsection{Profit Model}

Profit model is the pivotal factor of whether a business model can exist and develop. Through the profit model, the value provided by the enterprise to the customer is transformed into its own value. It is a kind of organization mechanism and commercial structure of realizing value creation, value acquisition, benefit distribution, which is formed by the integration of enterprise's own and related stakeholders' resources. Profit model can be divided into income structure, cost structure and corresponding target profit according to stakeholders. The income structure is the composition of the income source of the enterprise and the means by which the enterprise obtains income. Cost structure is the cost and resources that entrepreneurs pay for profit and value. Target profit refers to the expected income of the entrepreneur, that is, the estimate of input and output.

\subsection{Resource Ability}

Resource ability is the key for Enterprises to beat their competitors in Market Competition. Even a clever housewife cannot cook a meal without rice. Resource ability provides the means for the development of enterprises. It mainly includes two aspects. First, the basic resources that enterprises have, such as technology, talent, capital, management methods, etc., are essential elements for entrepreneurial success. Second, the enterprise has the core competitive ability, this core competitive ability is different from other enterprises, is the unique advantage in the competition, is scarce, difficult to copy and imitate. For example, product core technology, unique corporate culture, advanced production chain, unique logistics system and so on.

\subsection{External Effect}

The external effect here is different from the external effect in the general sense. It refers to a mode that can effectively maintain the culture and development direction of the enterprise. In the business model, the external effect is the driving force to promote the sustainable development of the enterprise. It can help the enterprise to make the profit model run effectively, the resource ability can be used synthetically, and the value can be created. External effect consists of two parts: partnership values and isolation mechanisms. The value of partnership refers to the value created by the enterprise through the cooperation with the relevant stakeholders in the course of its business activities, and it refers to the value of the industrial chain that the enterprise has. Isolation mechanism, simi- 
lar to a protection mechanism, is built by entrepreneurs to avoid imitating and destroying their own business models. It is of great significance for enterprises to maintain their own competitive advantages and promote the sustainable development of enterprises.

\section{The Path of Entrepreneurship in the "Internet+" Environment}

In the "Internet+" environment, we are in an era of cross-border integration. The competition at this time is no longer the competition of the general business model, in order to win in the wave of entrepreneurship, it is necessary to reconstruct the commercial value chain through the rational use of the Internet. Here we propose three ways to start a business under the "Internet+" environment.

\subsection{Cross-Border Business Model}

This model is mainly based on the Internet, and is a typical paradigm of traditional industry + Internet [1]. The biggest characteristic of this model is to improve the efficiency of resource allocation. By cross-border integration of a wide range of resources, further creates more value and realizes the value possession. Apple Inc. is a good example of cross-border success. It uses modern Internet technology and other new technological means to reshape its business model, from the software industry to the mobile phone manufacturing industry. In just a few years, it has occupied a broad market space in the international market. Apple Inc. achieved a leap forward. This mode is generally suitable for the transformation of enterprises, and it is difficult to operate in the process of starting a business. However, once successful, you can seize the market. Entrepreneurs need to have good personal qualities, loose market environment, strong policies and measures, etc. In addition, after the cross-border integration of resources, entrepreneurs should be able to achieve the integration of resources, in short, complete this kind of innovation and change, need the cooperation of various factors. Although this is difficult, if entrepreneurs can actively use the thinking of cross-border business models, grasp the inefficient or high-profit links in the traditional industry value chain, and use Internet tools and cross-border thinking to reconstruct the business value chain, the chances of success in starting a business will be greatly improved.

\subsection{Marginal Profit Business Model}

Marginal profit business model is another way to start a business under the "Internet+" environment, also known as the free model. The free business model refers to breaking the traditional industry model [4]. The enterprise has changed from relying on fee-based survival to relying on marginal revenue development, and changing the traditional charging mode into a free-to-play model. Free does not mean no profit, but by free to attract the attention of the users, based on the attention of the users to create value, and then convert into profit. For example, communication software represented by WeChat and QQ, social networking 
sites represented by Sina Weibo and Douban, and search engines represented by Baidu and Sohu are typical marginal revenue business models, all relying on good service and a lot of advertising revenue to achieve profitability. Through analysis, we can conclude that if entrepreneurs can give full play to the advantages and characteristics of modern Internet in the process of entrepreneurship, and carry out the network operation of entrepreneurial projects and expand the influence of entrepreneurial ideas and actions, they can form a good market effect. Then the entrepreneur will succeed in business.

\subsection{Platform Business Model}

The platform business model is the innovation of commodity trading activity mode. It makes use of the Internet technology to build a large enough platform and carries on the closed-loop design of the product service on the basis of attaching importance to the user experience [4]. On the basis of the above, to provide users with a variety of products and services. The outstanding characteristic of the platform business model is to use the network information technology to carry on the product on-line sale and the service, realizes the on-line and the offline mutual pull. This model has more profit space and more profit ways. The most representative platform is Taobao, JingDong Mall. This business model has greatly changed the traditional way of business operation. It makes the production, marketing and service of the product merge together organically, and achieves the goal of reducing the intermediate circulation link of the product, reducing the product cost and enhancing the efficiency of the product circulation. This model involves multiple stakeholders, entrepreneurs need to have a strong integration of resources, at the same time the platform must have great attraction.

\section{Conclusion}

Under the background of the rapid development of the Internet and the expanding influence, it has an impact on different fields all the time. A successful business model is always in keeping with the times. In the Internet era, entrepreneurs should keep up with the tide of the times, make full use of the opportunities brought by the Internet, actively respond to a series of challenges brought by the Internet, and build a business model in line with their own development and the requirements of the times in the opportunities and challenges.

\section{Conflicts of Interest}

The author declares no conflicts of interest regarding the publication of this paper.

\section{References}

[1] Fu, N. and Zhang, D.X. (2016) Analysis on the Business Model of College Students' Innovation and Entrepreneurship under the Environment of Internet. Market 
Modernization, 29, 241-242.

[2] Hu, F.F. (2018) Research on the Innovate and Entrepreneurial Model of College Students under the Background of Internet Plus. Henan University of Science and Technology, Luoyang.

[3] Morris, M., Schindehutte, M. and Allen, J. (2005) The Entrepreneur's Business Model: Toward a Unified Perspective. Journal of Business Research, 58, 726-735. https://doi.org/10.1016/j.jbusres.2003.11.001

[4] Wu, W.T. (2016) Analysis on the Business Model of College Students' Innovation and Entrepreneurship under the Environment of Internet. Innovation and Technology, 1.

[5] Zhao, L. (2017) Analysis on the Business Model of College Students' Innovation and Entrepreneurship under the Environment of Internet. China New Communications, 19, 141. 